\title{
For the safe flow of people in dental surgeries
}

The company behind some of the UK's most exciting and dynamic interactive exhibition displays in visitor attractions and museums has brought to market QCounter - a fully automated, but low-cost, access control/ people-counter system.

Businesses emerging from lockdown restrictions must limit the number of people accessing a space or building to ensure the site remains COVID-safe and compliant with government regulations.

QCounter, based on a traffic light system, is a fully automated (without the need for any human operation), 'Plug n' Play' customer/ visitor/staff counting system that manages and ensures the safe flow of people through spaces - thus ensuring organisations remain COVID-safe whilst fully operational.

QCounter provides the following functionality:

- Fully automated - no staff/personnel remote control operation required (unlike other systems)

- Ergonomic design

- Large bright indication of status (based on traffic light system)

\section{Flagship event set for Glasgow}

The British Society of Dental Hygiene and Therapy (BSDHT) is excited to announce that its flagship event, the Oral Health Conference (OHC) will be taking place in Glasgow on 26-27 November 2021.

The $\mathrm{OHC}$ is the perfect opportunity for dental hygienists, dental therapists and students of the profession to network with likeminded individuals, keep up to date with the latest research in the field and expand in their careers.

As always, the show will see a number of exciting lectures, hands-on workshops and product demonstrations, plus offer the chance to catch up with colleagues and meet new people who share your passions and interests.

So, make sure to put the date in your diaries if you don't want to miss out!

For more information about the BSDHT, visit www.bsdht.org.uk, call 01788575050 or email enquiries@bsdht. org.uk.

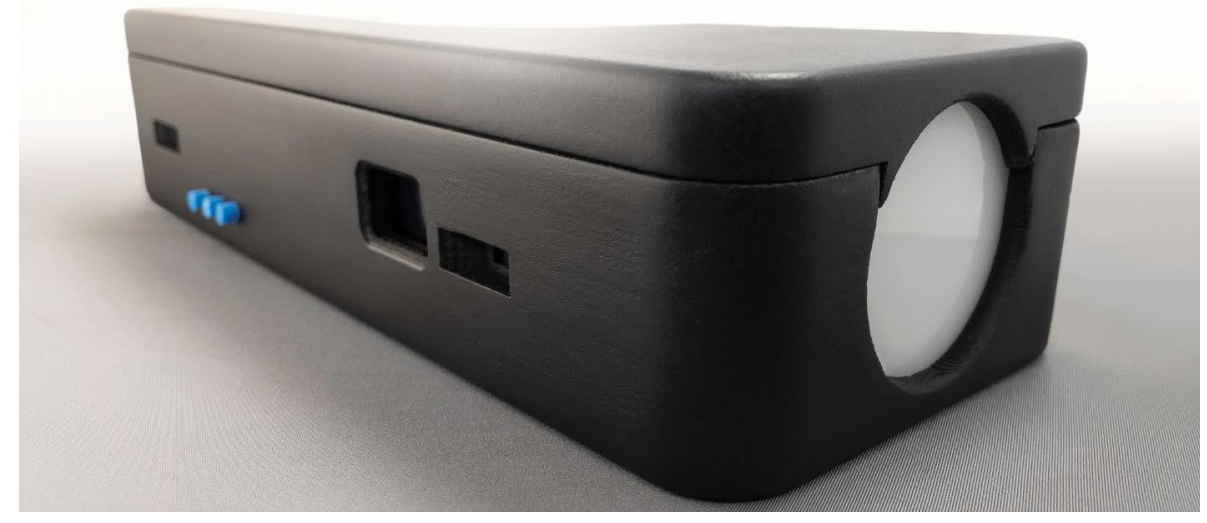

- Integrated LCD information display

- Easy-to-change number of people allowed

- Powered by dc supply from mains plug or USB power bank

- Portable and easy to mount to any standard retractable barrier post - no tools required

- Both single and dual units versions available - works on one way system with separate in and out doors

- Client-branded 'dashboard' webpage (for public visibility).

Operational benefits for client:

- Compliance with COVID secure rules
- Visual reassurance for customers/visitors/ staff/guests

- Non-language specific

- GDPR compliant (no integrated cameras)

- Webpage can be displayed on larger screen to further reassure compliance

- Expansion options available.

The units have been designed and manufactured in the UK by UK conceptto-reality company FifeX and are available to order today from their dedicated website www.qcounter.co.uk.

\section{Naturally enhanced recovery}

Invasive dental procedures can leave the oral cavity vulnerable to plaque build-up. You can help patients optimise their recovery from treatment by recommending 'Perio plus' Forte mouth rinse.

It contains the highest concentration of chlorhexidine from the 'Perio plus' product range for a highly effective result. Designed for short-term use, 'Perio plus' Forte combines the benefits of chlorhexidine with those of Citrox - a broadspectrum anti-microbial substance extracted from bitter oranges.

Citrox naturally enhances the effects of chlorhexidine to create a high-performance mouth rinse that protects the oral cavity, with minimal risk of irritation, discolouration and disruption to taste.

Discover the complete range of 'Perio plus' mouth rinses online today.

For more information call 01480 862084, email info@curaprox.co.uk or visit www.perioplus.com/uk.

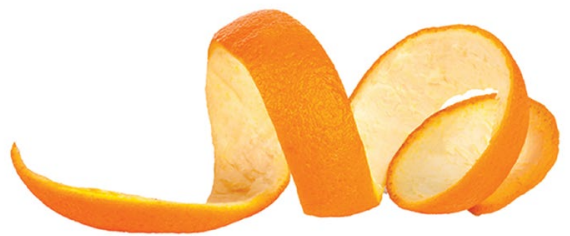

